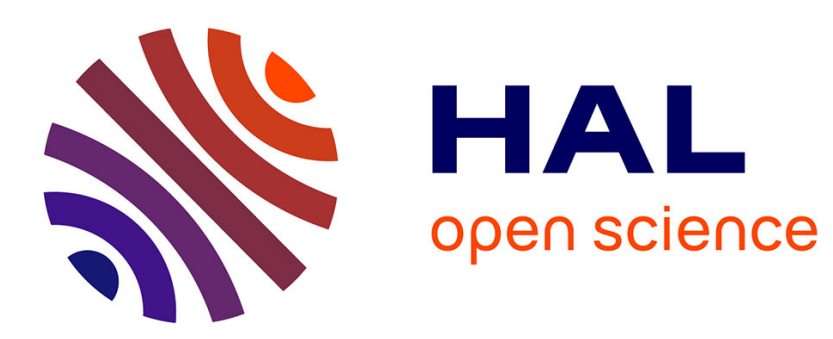

\title{
Quantum chemical study on the ground state alcoholic complexation of selected dual luminescent compounds
}

\author{
Gergely Tóth, Attila Demeter, Viktoria Mile
}

\section{To cite this version:}

Gergely Tóth, Attila Demeter, Viktoria Mile. Quantum chemical study on the ground state alcoholic complexation of selected dual luminescent compounds. Molecular Physics, 2009, 107 (19), pp.19871996. 10.1080/00268970903084953 . hal-00519621

\section{HAL Id: hal-00519621 \\ https://hal.science/hal-00519621}

Submitted on 21 Sep 2010

HAL is a multi-disciplinary open access archive for the deposit and dissemination of scientific research documents, whether they are published or not. The documents may come from teaching and research institutions in France or abroad, or from public or private research centers.
L'archive ouverte pluridisciplinaire HAL, est destinée au dépôt et à la diffusion de documents scientifiques de niveau recherche, publiés ou non, émanant des établissements d'enseignement et de recherche français ou étrangers, des laboratoires publics ou privés. 


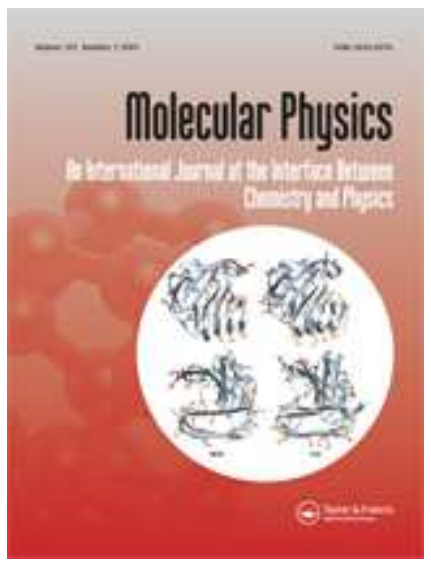

\section{Quantum chemical study on the ground state alcoholic complexation of selected dual luminescent compounds}

\begin{tabular}{|r|l|}
\hline Journal: & Molecular Physics \\
\hline Manuscript ID: & TMPH-2009-0096.R1 \\
\hline Manuscript Type: & Full Paper \\
\hline Date Submitted by the \\
Author: & $29-$ May-2009 \\
\hline $\begin{array}{r}\text { Complete List of Authors: } \\
\end{array}$ & $\begin{array}{l}\text { Tóth, Gergely; Institute of Chemistry, Eötvös University } \\
\text { Demeter, Attila; Institute of Materials and Environmental } \\
\text { Chemistry, Chemical Research Center } \\
\text { Mile, Viktoria; Institute of Chemistry, Eötvös University }\end{array}$ \\
\hline Keywords: & complex formation, dipole moment, dual luminescence \\
\hline
\end{tabular}

\section{$\checkmark$ ScholaroNE" \\ Manuscript Central}


V. Mile et al.

\title{
Quantum chemical study on the ground state alcoholic complexation of selected dual luminescent compounds
}

\author{
Viktória Mile, ${ }^{\mathrm{a}, \mathrm{b}}$ Attila Demeter ${ }^{\mathrm{b}}$ and Gergely Tóth ${ }^{\mathrm{a} *}$ \\ ${ }^{a}$ Institute of Chemistry, Eötvös Loránd University, Budapest P.O. Box 32, 1518 Hungary \\ ${ }^{b}$ Institute of Materials and Environmental Chemistry, Chemical Research Center, Hungarian \\ Academy of Sciences, Budapest, Pusztaszeri u. 59-67, 1025 Hungary
}

\begin{abstract}
The ground and excited state features of dual luminescent molecules are strongly influenced by the presence of alcoholic additives. Selected ground state properties of methanol and 1,1,1,3,3,3-hexafluoro-propan-2-ol complexes of 4-aminobenzonitrile, 4-aminopyridine and aniline derivatives are obtained by quantum chemical calculations. The formation enthalpies of the complexes are the most exothermic when the cyano or ring nitrogen interacts by the hydroxyl group of the alcohols. The binding energies are almost doubled when the fluorinated reactant is the hydrogen bond donor. Parallel with the enhancement of the stabilization of the complex, the ground state dipole moment also increases notably with the complex formation. In principle, consideration of this enlargement is essential in interpretation of the solvatochromatic behaviour of the complexed species.
\end{abstract}

Keywords: complex formation, dipole moment, dual luminescence

*To whom correspondence should be addressed (toth@chem.elte.hu) 


\section{Introduction}

The mechanism of photoinduced intramolecular electron transfer reactions has been paid substantial current interest in chemistry and biochemistry. Donor-acceptor substituted aromatics or bichromorphic dyads of donor-acceptor compounds are the simplest model systems where intramolecular electron transfer can be studied. Some of these substances show dual luminescence observed first by Lippert and coworkers. ${ }^{1,2}$ Here, the molecule is excited to a locally exited state (can be characterized by similar geometry and solvation than that of the ground state), however after solvent and structural relaxation an intramolecular charge transfer (ICT) state can be formed in an often reversible reaction. The system emits differently from the two states, the ICT emission commonly shows strong batochromic shift, and the shape and the position of the spectra depend on the nature of the solvent. The dual luminescence phenomenon was first observed ${ }^{1,2}$ and frequently studied ${ }^{3-7}$ on the molecule of 4-(dimethylamino)benzonitrile (DMABN). It was revealed, that the formation of hydrogen bonded alcoholic complexes stabilizes the charge transfer state. ${ }^{4,5}$ The photophysics of the smallest DMABN-like dual luminescent molecule, 4-(dimethylamino)pyridine (DMAP) was studied experimentally in different laboratories ${ }^{8-14}$ as well. It was concluded that the excited molecule emits dual luminescence with the characteristics of the reversible two-state systems in polar solvents, while the long wavelength fluorescence is almost unobservable in $n$ hexane. ${ }^{8,9,13-15}$ An experimental study has been published recently on the photolysis of DMAP in the presence and absence of different aliphatic alcohols and fluorinated aliphatic alcohols in various solvents by the authors of this paper. ${ }^{15}$ As an effect of hydrogen bond formation in the apolar $n$-hexane the ICT emission becomes dominant, while in polar solvents a polarity dependent red shift is observable, indicating a strong increase of the excited state dipole moment of the ICT state with complexation. It was indicated, that the magnitude of the experimentally derived dipole moment of the ICT state of DMAP and its singly complex derivative (in apolar solvents) favours more the occurrence of the planar structure of the species in question. A continuous effort was made in this work, as done it before, ${ }^{16-18}$ to quantify the key thermodynamic, spectroscopic and kinetic properties of alcoholic complexes of selected aromatic amide and imide model compounds.

There are several theoretical investigations focused on the properties of dual luminescent molecules, most of them concerns DMABN. The state of the art was surveyed by Grabowski et al. ${ }^{5}$ in 2003 . The theoretical calculations were mostly devoted to validate the twisted or planar structure of the intramolecular charge transfer states in the excited states. ${ }^{3,19}$ Recently, Kohn and Hattig performed coupled cluster ab initio calculations on the exited states and they showed the preference of the twisted state. ${ }^{20}$ Similar conclusion was obtained by Grimme and Ugorodine using coupled cluster and time-dependent density functional calculations. $^{21}$ The main results were reinforced in two later studies, ${ }^{22,23}$ when the theoretical calculations explained the lack of dual fluorescence in case of 4-aminobenzonitrile (ABN). However, new experimental evidences appeared in the last years demonstrating that the twisting of the electron donating group to the perpendicular conformation is not in the least a requirement of the appearance of the red shifted ICT emission in case of the DMABN related compounds. $^{24,25}$

The number of the theoretical studies on DMAP is much less than for DMABN. Cazeau-Dubroca et al. ${ }^{8}$ performed calculations with semi-empirical methods in 1994 and showed that the dimethylamino group is twisted in the ground state induced by hydrogenbonded water. The hydrogen bond was located on the amino nitrogen of DMAP, and they found this twisting as a general phenomenon for flexible aromatic molecules. Herbich and Waluk ${ }^{9}$ published a combined experimental/theoretical study on DMAP and on its pyrimidine analogues. Their mostly experimental results clearly showed the strong dependence of the 
shape of the fluorescence spectra on the formation of the hydrogen-bonded complexes. Ringmethylated derivatives of DMAP were investigated with time-dependent density functional calculations by Szydlowska et al. ${ }^{11,12}$ in 2003 . Basically, they were interested on the geometry of the excited intermolecular charge transfer state, and found - as they expected - that the ICT structure is twisted.

The aim of our present study is to describe the basic features of the alcoholic complexes of 4-aminobenzonitrile, 4-aminopyridine and aniline derivatives. We focused on ground state properties, e.g. on the structure and stability of the complexes, and on the important geometrical changes caused by the complex formation. Another intention of the study was to get further support for the identification of the nitrogen, involved in the primary complexation step. The computations were performed with the simplest alcohol, i.e. methanol; however, some calculations were carried out on the complexes of the strong hydrogen bond donor 1,1,1,3,3,3-hexafluoro-propan-2-ol (HFIP), as well. The calculations were accomplished mostly for gas-phase complexes, but for a few systems simple solvent models were included to get some indication on the effect of solvation. Ground-state dipole moments of the complexed molecules were estimated, in order to provide data for the evaluation of previous ${ }^{15}$ and further experimental data. A possible step of further investigations might be a set of systematic and comprehensive excited state calculations on the complexes.

\section{Calculation details}

Three groups of molecules were studied in our calculations. The first one corresponds to 4-(dimethylamino)benzonitrile (DMABN) and related compounds: benzonitrile (BN), 4aminobenzonitrile (ABN), 4-(methylamino)benzonitrile (MABN). The second group includes 4-(dimethylamino)pyridine (DMAP), pyridine (PY), 4-aminopyridine (AP) and 4(methylamino)pyridine (MAP). The third one is the N,N-dimethylaniline (DMAN) group: aniline (AN) and N-methylaniline (MAN). The schematic structure of the compounds can be seen in Figure 1.

\section{(Figure 1)}

The calculations were performed using density functional method (DFT). Becke's three parameter hybrid functional was used with the Lee-Yang-Parr correlation one, generally known as B3LYP. ${ }^{26}$ The standard $6-311 \mathrm{G}++(\mathrm{d}, \mathrm{p})$ basis set was applied, which contains diffuse functions to improve the description of the hydrogen bonds. The calculations were performed with the Gaussian program package. ${ }^{27}$ First, the optimized geometry of the isolated compounds was determined, then the complexes were put together manually from the two optimized geometries, e.g. one aromatic compound and the methanol molecule and the geometries of the complexes were optimized. Normal mode analysis was performed for each optimized structure.

The binding energy of a complex is defined as the difference between the energy of the complex and the isolated constituents. In case of quantum-chemical calculations, it is necessary to take into account the basis set superposition error. Instead of using the standard procedure proposed by Boys and Bernardi, ${ }^{30}$ we applied a modified recipe taking into account the geometrical relaxation as well. ${ }^{31}$

$$
\begin{aligned}
& \Delta E(A H)=E^{A H}\left(A H, A H_{\text {geom }}\right)-\left[E^{A}\left(A, A_{\text {geom }}\right)+E^{H}\left(H, H_{\text {geom }}\right)\right] \\
& +\left[\left(E^{A}\left(A, A H_{\text {geom }}\right)+E^{H}\left(H, A H_{\text {geom }}\right)\right)-\left(\left(E^{A H}\left(A, A H_{\text {geom }}\right)+E^{A H}\left(H, A H_{\text {geom }}\right)\right)\right]\right.
\end{aligned}
$$


where $\mathrm{A}$ and $\mathrm{H}$ denote the alcohol and the aromatic molecules, respectively. The upper indexes refer to the applied basis sets. For example ${ }^{\mathrm{AH}}$ means that both sets were present. In a case of only one constituent, the only the basis set of the other molecule is included, its nucleus and electrons were not (a set ghost atoms). The first letters in the parentheses refer to the calculated compounds, while the letters with geom subscript means whether the free $\left(\mathrm{A}_{\text {geom }}\right.$ or $\left.\mathrm{H}_{\text {geom }}\right)$ or the complexed $\left(\mathrm{AH}_{\text {geom }}\right)$ geometry of the respective fragments are used. For example, $E^{A H}\left(H, A H_{\text {geom }}\right)$ means the energy calculated for an aromatic fragment with both basis sets, at the geometry of the optimized complex.

\section{Results and discussions}

\section{Isolated compounds}

Selected geometrical parameters, atomic charges and vibrational frequencies of the isolated methanol molecule and the nitrogen-containing aromatic substrates are summarized in Tables 1 and 2. These well-known data are used as a reference in the discussion of the changes caused by the complex formation.

\section{(Table 1)}

In Table 2 the notation of the optimized bond angles and bond distances corresponds to the schematic representation in Figure 1. The Mulliken charges of the nitrogen atoms are also included in the table. We present dipole moments and vibration frequencies as well, because these data are rather useful in the data evaluation of experimental spectra. ${ }^{15}$ Those data are selected, which are supposed to change significantly during the complex formation.

\section{(Table 2)}

The electron-donor property of the methyl group can be clearly detected both in the 4aminopyridine and the aniline derivatives: the charges on the $\mathrm{N}$ atoms increase monotonically with the number of the methyl groups. The situation is different for the DMABN group where introduction of the second $\mathrm{CH}_{3}$ group reduces the charges of both $\mathrm{N}$ atoms as compared to MABN. Methyl substitution also has an effect on the anylinic C-N $\left(d_{3}\right)$ bond length: while the first $\mathrm{CH}_{3}$ group lengthens of the $\mathrm{C}-\mathrm{N}$ (No. 3) bond, the second reduces it almost back to the value in the amine.

These structural data of DMAP can be compared to experimental ${ }^{28,29}$ as well as other theoretical data $^{12}$ (Table 3 ). The experimental values were determined with X-ray diffraction method. The theoretical calculation of Szydlowska and co-workers was performed similarly as we have done. Their standard basis set was slightly smaller, but they used more polarization functions. The overall agreement of the three sets of structural data is good. There are notable differences only in the dipole moments. We obtained 4.83 D, Szydlowska et al. calculated $4.55 \mathrm{D}$, the latter being closer to the experimental value, $4.22 \mathrm{D}$ (we note, however, that these differences are in the range of uncertainty of the calculation, moreover the experimental value also must have an approx. $20 \%$ error as well).

\section{(Table 3)}

\section{Methanol complexes}

Three different isomers of the complexes formed by the studied molecules with methanol can be imagined. In the 'a' case, the hydrogen of the amino group interacts with the 
oxygen atom of methanol. In the 'b' form, the hydrogen donor is the hydroxyl group of methanol and the acceptor is the nitrogen atom of the amino group. In the third arrangement (denoted as ' $c$ '), the hydrogen bond is formed between the non-amino nitrogen atom of the aromatic compound and the hydroxyl hydrogen of the methanol. Not all isomers of the complex can be realized by all investigated compounds. Formation of an 'a' type complex is possible for ABN, MABN, AP, MAP, AN, and MAN. 'b' type complexes can be formed for all species except BN and PY. No 'c' complex can be formed by aniline and its derivatives.

The corrected binding energies calculated according to Eq. (1) are collected in Table 4. The weakest hydrogen bond was found for DMAP in position ' $b$ '. It is even weaker than the DMAN - methanol binding energy, and supports the assumption derived from experimental observations, namely, that DMAP forms primarily a 'c' type complex. The most stable complex is formed by $\mathrm{ABN}$, the most strongly bound being the ' $\mathrm{c}$ ' isomer, but the energy difference between the ' $a$ ' and ' $c$ ' positions is within the uncertainty of the calculations. The same applies to the ' $a$ ' and ' $c$ ' isomers of MABN. The MABN - methanol bond is weak as compared to ABN and DMABN. Similarly, the partial charge of the amino nitrogen is high in the ' $b$ ' complexes of DMAP and DMAN. This increase in the partial charge and the steric hindrance of the dimethyl part of the dimethylamino groups are manifested in weak hydrogen bonds. In the case of the 'c' complexes, the large partial charges on the aromatic nitrogen induce strong binding. However, on contrary to the large partial charge of the cyano nitrogen in MABN, the complex seems to be less stable than that one might expect. To check the reliability of binding energy calculations we have determined the equilibrium constants of the hydrogen-bonded complex formation process of the cyano derivatives with HFIP in n-hexane (which parameter is related to the Gibbs energy change of the reaction) as it was described in details in Reference 15 . The derived parameters were $26 \pm 5,90 \pm 10,36 \pm 5,126 \pm 10 \mathrm{~mol}^{-1} \mathrm{dm}^{3}$, for $\mathrm{BN}, \mathrm{ABN}, \mathrm{MABN}$, and DMABN, respectively. The variation of the experimental data straightforwardly follows the fluctuation of the calculated binding energies. (The partial charge on the nitrogen atoms does not give us a proper indication of the strength of the forming hydrogen bond, at least at the level (method) of the present study.)

\section{(Table 4)}

The correction of the basis set superposition error was positive in all cases and the usage seemed to be essential. We calculated the percentage effect of the correction as $100 *\left(\Delta E_{\mathrm{BSSE}^{-}}\right.$ $\Delta E) / \Delta E_{\mathrm{BSSE}}$, where $\Delta E$ and $\Delta E_{\mathrm{BSSE}}$ mean the uncorrected and the corrected binding energies. The less effected case was the 'c' position. Here the range of the percentages was between 2.78.6 \%. In the 'a' case it was 4.1-15.1\%. The highest correction was for the 'b' position: from 5.3 to $26.6 \%$. This trend can be explained with the number of the methyl groups. Several basis functions are accessible for the other molecule in the ' $b$ ' case, while it is rather limited for the 'c' situation. According to this, the correction increased with the number of the methyl groups as well.

The length of the hydrogen bond was studied as the equilibrium distance of the electron donor oxygen or nitrogen and the hydrogen taking part in the complex formation, $d_{(\mathrm{A} . \mathrm{H})}$. In the case of the 'a' position, $d_{\mathrm{a}}$ means the distance between the amino hydrogen and the methanol oxygen. $d_{\mathrm{b}}$ denotes the distance of the amino nitrogen and the hydroxyl hydrogen, and $d_{\mathrm{c}}$ is the distance of the nitrogen in the ring or the cyano group and the hydroxyl hydrogen. Besides these distances the $\varphi_{\mathrm{O}-\mathrm{H}-\mathrm{N}}$ hydrogen bond angles are also shown in Table 5 . The distances of the hydrogen bonds are related to the strength of the interactions. The data correlate well with the binding energies, shown in Table 4 . The 'a' type interactions are preferred in the case of the benzonitrile derivatives and the 'c' position seems to be the best for the aminopyridine ones. The hydrogen bond distances are shorter in the 'b' type aniline 
derivatives than in the 'a' case. The electron donor feature of the methyl groups increased the partial charges on the nitrogen atoms. It causes a shortening in the length of the hydrogen bond of the aniline derivatives and in the case of 'c' complexes of the other compounds. In the case of the ' $a$ ' and ' $b$ ' complexes, the partial charge of the amino nitrogen is larger than on the other nitrogen. Therefore, it may effect the bond length besides the steric effect of the methyl group and probably there is only a small increase in the distances with increasing number of methyl groups. The bond angles reflect the spatial effects. The ' $c$ ' complexes have linear hydrogen bonds, while the ' $b$ ' ones can be distorted to $161^{\circ}$.

\section{(Table 5)}

The important changes in the molecules during the complex formation are summarized in Table 6. We present here the dipole moments of the complexes, the length and frequency changes of the $\mathrm{N}-\mathrm{H}$ bonds and the variation of the nitrogen partial charges. In the case of the amino derivatives, the asymmetric vibrations are shown. The change of the ring $-\mathrm{N}\left(d_{3}\right)$ bond length is shown as well, since Szydlowska and co-workers found this value to be the most sensitive to the changes in the solvent. ${ }^{12}$ The variation of the data corresponding to the methanol part of the complex $\left(\Delta d_{\mathrm{OH}}, \Delta v_{\mathrm{OH}}\right)$ appears in Table 6 , too.

The $\mathrm{N}-\mathrm{H}$ bond increases with around the value of $0.05 \AA$, if it takes part in the hydrogen bond. An exception is the ABN complex, where the distance does not change. In the case of ' $b$ ' complexes, where hydrogen connects to the amino nitrogen, there is an increase in the bond distances, but the effect is less than in the 'a' case. In the ABN complex, one can observe a shortening in the bond length. It can be explained with the increased partial charge on the amino nitrogen. Similar decrease can be detected on the 'c' complex of ABN as well, but in the other complexes the effect of the hydrogen bond formation is negligible due to the large intermolecular distances. The ring $-\mathrm{N}$ bond distance, $d_{3}$, is sensitive to the complex formation. The changes are even larger $(-0.064$ to $+0.038 \AA)$ than the variation of the hydroxyl $\mathrm{O}-\mathrm{H}$ length. For example, there is no change in the $\mathrm{O}-\mathrm{H}$ bond length, if the oxygen is the donor of the hydrogen bond. The $\mathrm{O}-\mathrm{H}$ bond length increases, if the hydroxyl hydrogen takes part in the complex formation, above all in the case of the pyridine derivatives. The effect is two times larger than that for the benzonitrile derivatives and 1.5 times larger than for the aniline derivatives. These trends can be detected in the vibrational frequencies as well, and the data support the assumption that the pyridine derivatives have a strong hydrogen bond forming character. The partial charge on the pyridine nitrogen decreases in the ' $b$ ' complexes and increases in the 'a' and especially in the ' $c$ ' cases. This observation is in accordance with our previous findings ${ }^{15}$ that the formation of the ' $c$ ' type hydrogen bond enhances the charge separation in the ground state, and increases the negative partial charge on the pyridine nitrogen.

Cazeau-Dubroca et al. ${ }^{8}$ investigated the position of the hydrogen bond and its effect on the dual fluorescence. They concluded that the complexation occurs on the amino nitrogen atom. In the DMAP $-\mathrm{H}_{2} \mathrm{O}$ system, they proposed that even the ground state complex formed in a twisted conformer (where the plane of the complexed dimethylamino group is almost perpendicular to the aromatic ring), with an energy gain of $15 \mathrm{~kJ} / \mathrm{mol}$. They supposed that this structure favours the formation of the twisted ICT exited state. However, our calculation indicates that in the primary complexation step the hydrogen bond formation must occur on the pyridine nitrogen, in accordance with the results of Szydlowska et al. ${ }^{14,32,33}$

In evaluation of the data of spectroscopic experiments (as for example solvatochromic measurements) the knowledge of the ground state dipole moments is essential. The dipole moments of the complexes are given in Table 6. The ' $a$ ' and 'c' complexes have definitively larger dipole moments than the isolated molecules. On contrary, the 'b' complexes can be 
characterised usually by smaller or similar dipole moments values than the uncomplexed molecule.

(Table 6)

\section{Hexafluoro-propan-2-ol complexes}

In our earlier paper the photophysics and the dual luminescent properties of DMAP was investigated in the presence of different aliphatic and fluorinated aliphatic alcohols. ${ }^{15}$ The principal investigated fluorinated alcohol was 1,1,1,3,3,3-hexafluoro-propan-2-ol (HFIP). Similarly what is presented for the complexes formed with methanol, we also studied the properties of the HFIP-complexed molecules. The calculations were focused on DMAP, as it was done in the experiments. The methodological details of the calculation were the same as in the "methanol case"; in addition the results for the four examined complexes are summarized in Table 7. The binding of these complexes are significantly stronger than that was observed for the methanol complexes. In the ' $c$ ' positions of pyridine and 4(dimethylamino)pyridine the binding energies are almost two times higher in the HFIPderived than in the methanol complexes (see Table 4). The trends are also similar; the ' $c$ ' DMAP complex is preferred compared to the ' $b$ ' isomer. This is reflected in the hydrogen bond lengths as well that are shortened by 0.1-0.2 pm. The dipole moments are 3-4 Debye higher in the HFIP complexes, and the changes of the partial charges indicate strong interactions as well. The calculations show that the HFIP complexes are much more stable than the methanol ones. The changes in the charges are rather large and the growth of the dipole moments is significant.

\section{(Table 7)}

\section{Solvent effects on DMAP}

The photophysical studies on dual luminescent molecules and their complexes are performed almost exclusively in solution. The compounds are dissolved in an appropriate solvent and small amount of complex forming substance, e.g. alcohol is added to the solution. The concentration of the alcohol is sometimes controlled to provide $1: 1$ or $1: 2$ aromatic/alcohol complexes. ${ }^{15}$ The explicit model of these conditions cannot be used in quantum mechanical calculations, because the computational limit is far away to incorporate sufficient number of solvent molecules. A simple and practical method is to treat the solvent as a dielectric continuum mutually interacting with the quantum chemically modelled molecule. We applied in our calculation the polarizable conductor calculation model (PCM) that bases on the general technique of the self-consistent reaction field method. ${ }^{34}$ Table 8 contains the results of our calculation on 4-(dimethylamino)pyridine in different solvents. Only those distances are selected for presentation, which change significantly. The influence of the following solvents were examined: cyclohexane $(\mathrm{CH})$, carbon tetrachloride $\left(\mathrm{CCl}_{4}\right)$, diethyl ether (DEE), chlorobenzene (ClBz), tetrahydrofurane (THF), and acetonitrile (ACN), ordered with increasing empirical solvent polarity of Dimroth and Reichardt. ${ }^{35}$ One can see that the extent of the changes in the equilibrium structure increased with the solvent polarity. The most sensitive part of the molecule is the distance between the aromatic ring and the amino nitrogen, as was observed before in different aspects. The raise of the solvent polarity increases significantly the negative partial charge on the pyridine nitrogen (see Table 8), while it is decreased slightly on the amino nitrogen atoms. The most important effect is a significant increase in the dipole moments, which results in the $40 \%$ growth of the value in the most polar acetonitrile. The comparable data correspond well to the calculated results of 
Szydlowska et al. ${ }^{12}$ performed with the polarizable continuum model ${ }^{36}$ and to the calculation of Sudholt et. al. ${ }^{37}$

\section{(Table 8)}

It should be noted here, that there is a quantum chemical study on water - methylsubstituted pyridine complexes, ${ }^{38}$ where the performance of the density functional method and the Moller-Plessset second order perturbation theory were compared for these systems. In the case of the meta- and para-substituted compounds, the binding energy of the complexes were comparable with the two calculation methods. In the case of the orto-substituted pyridine, the dispersion interaction of the methyl groups and the water was underestimated in the density functional calculations. It was also valid for the $\pi . . . \mathrm{H}-\mathrm{O}$ type interactions, the obtained binding energies were smaller than ones got with the other calculation method. This type of interactions cannot be excluded in our ' $b$ ' positioned complexes, therefore the uncertainty of the results concerning the ' $b$ ' positions is larger than in the 'a' and 'c' cases. It may concern the results on $\mathrm{ABN}$, therefore calculations are in progress with improved, more adequate methods for the ABN-methanol complexes.

\section{Conclusions}

Selected ground state properties of the isolated DMABN, DMAP and DMAN derivatives and their methanol-derived complexes were calculated. Three types of complexes were considered: 'a' - the hydrogen of the amino group interacts with the oxygen atom of methanol, ' $b$ ' - the nitrogen of the amino group interacts with the hydroxyl hydrogen of methanol, and ' $c$ ' - the nitrogen of the ring or the cyano group interacts with the hydroxyl hydrogen of methanol. The calculations indicate that the 'a' and the 'c' positions are preferred for $A B N$ and MABN, and the ' $c$ ' for DMABN. The ' $c$ ' type is energetically favoured for the DMAP derivatives. In the aniline group, the formation of the ' $b$ ' complex is more exothermic than the ' $a$ ' one. The binding energy data correlate well to the structural changes of the hydrogen bond, to the modification of partial charge values, as well as to the corresponding shifts of vibration spectra. The most sensitive structural parameter was the distance between the aromatic ring and the amino group. The pre-twisting effect reported by Cazeau-Dubroca et al. ${ }^{8}$ is not probable at all in the primary complexation step, however the new results resemble rather to the recent results of Szydlowska et al. ${ }^{14,32,33}$ including 4-diethylaminopyridine and 4diisopropylaminopyridine complexes, as well.

Similar calculations were performed on the HFIP complexed DMAP derivatives. These species were outstandingly stable compared with the methanol derived ones. The enhancement in ground state dipole moments, as well as the increase of the binding energies is 1.5-2 times larger in the case of the HFIP complexes.

The effect of the solvent surrounding on the equilibrium structure and dipole moment of isolated DMAP was examined using the polarizable conductor calculation model. An increasing negative partial charge on the pyridine nitrogen and significant growth in the dipole moments with increasing solvent polarity were observed. Mainly, the distance of the pyridine and the amino group was effected by the solvents.

The data derived in this study may provide a quantitative basis in the further understanding of the solvent dependent dual fluorescence in the presence of complex forming materials. Especially the knowledge of enlargement of the ground state dipole moments with complex formation is essential in the interpretation of the solvatochromatic behaviour of the complexed species.

\section{Acknowledgement}


This work was supported by the Hungarian Science Foundation (OTKA T45890 and OTKA T43542). 


\section{References}

${ }^{1}$ E.Lippert, W.Lüder, and H.Boos, Advances in Molecular Spectroscopy; European Conference on Molecular Spectroscopy, Bologna, Italy, 1959; Ed.: A.Mangini; Pergamon: Oxford, 1962.

${ }^{2}$ E.Lippert, W.Lüder, F.Moll, H.Nägele, H.Boos, H.Prigge, and I.Seibold-Blankenstein, Angew. Chem. 73, 695 (1961).

${ }^{3}$ K A. Zachariasse, Chem. Phys. Lett. 320, 8 (2000).

${ }^{4}$ W. M. Kwok, C. S. Ma; M. W. George, D. C. Grills, P. Matousek, A. W. Parker, D. Phillips, W. T. Toner, and M. Towrie, Phys. Chem. Chem. Phys. 5, 1043 (2003).

${ }^{5}$ Z. R. Grabowski, K. Rotkiewicz, W. Rettig, Chem. Rev. 103, 3899 (2003).

${ }^{6}$ K. Dahl, R. Biswas, N. Ito, and M. Maroncelli, J. Phys. Chem B 109, 1563 (2005).

${ }^{7}$ S. I. Druzhinin, N. P. Ernsting, S. A. Kovalenko, L. W. Lustres, T. A. Senyushkina, and K. A. Zachariasse, J. Phys. Chem A 110, 2955 (2006).

${ }^{8}$ C. Cazeau-Dubroca, G. Nouchi, M. Ben Brahim, M. Pesquer, D. Gorse, Ph. Cazeau, J. Photochem. Photobiol. A 80, 125 (1994).

${ }^{9}$ J. Herbich, J. Waluk, Chem. Phys. 188, 247 (1994).

${ }^{10}$ S. Mishina, M. Takayanagi, M. Nakata, J. Otsuki, K. J. Araki, J. Photochem. Photobiol. A 141, 153 (2001).

${ }^{11}$ I. Szydlowska, A. Kyrychenko, J. Nowacki, J. Herbich, Phys. Chem. Chem. Phys. 5, 1032 (2003).

${ }^{12}$ I. Szydlowska, A. Kyrychenko, A. Gorski, J. Waluk, J. Herbich, J. Photochem. Photobiol. Sci. 2, 187 (2003).

${ }^{13}$ I. Szydlowska, J. Kubicki, J. Herbich, J. Photochem. Photobiol. Sci. 4, 106 (2005).

${ }^{14}$ I. Szydlowska, J.Nowacki, A. Zielinska, and J. Herbich, Polish J. Chem., 82, 847 (2008).

${ }^{15}$ A. Demeter, V. Mile, T. Bérces, J. Phys. Chem. A 111, 8942 (2007).

${ }^{16}$ A. Demeter, L. Ravasz, T. Bérces, J. Phys. Chem. A 108, 4357 (2004).

${ }^{17}$ A. Demeter, React. Kinet. Catal. Lett. 85, 331 (2005).

${ }^{18}$ A. Demeter, and T. Bérces, J. Phys. Chem. A 109, 2043 (2005).

${ }^{19}$ K. Rotkiewicz, K. H. Grellmann, and Z. R. Grabowski, Chem. Phys. Lett., 21, 212 (1973); Chem. Phys. Lett. 21, 315 (1973).

${ }^{20}$ A. Kohn, C. Hattig, J. Am. Chem. Soc. 126, 7399 (2004).

${ }^{21}$ S. Grimme and E. I. Ugorodina, Chem.Phys. 305, 2232 (2004).

${ }^{22}$ X. F. Xu, Z. X. Cao, and Q. N. Zhang, J. Chem. Phys. 122194305 (2005).

${ }^{23}$ I. Gomez, M. Reguero, M. Boggio-Pasqua, and M.A. Robb, J. Am. Chem. Soc., 7, 7119 (2005).

${ }^{24}$ K. A. Zachariasse, S. I. Druzhinin, W. Bosch, and R. Machinek, J. Amer. Chem. Soc. 126, 1705 (2004).

${ }^{25}$ T. Yoshihara, S. I. Druzhinin, and K. A. Zachariasse, J. Amer. Chem. Soc. 126, 8535 (2004).

${ }^{26}$ A. D. Becke, J. Chem. Phys. 98, 5648 (1993).

${ }^{27}$ K M. J. Frisch, G. W. Trucks, H. B. Schlegel, G. E. Scuseria, M. A. Robb, J. R. Cheeseman, V. G. Zakrzewski, J. A. Montgomery, Jr., R. E. Stratman, J. C. Burant, S. Dapprich, J. M. Millam, A. D. Daniels, K. N. Kudin, M. C. Strain, O. Farkas, J. Tomasi, V. Barone, M. Cossi, R. Cammi, B. Mennucci, C. Pomelli, C. Adamo, S. Clifford, J. Ochterski, G. A. Petersson, P. Y. Ayala, Q. Cui, K. Morokuma, D. K. Malick, A. D. Rabuck, K. Raghavachari, J. B. Foresman, J. Cioslowski, J. V. Ortiz, A. G. Baboul, B. B. Stefanov, G. Liu, A. Liashenko, P. Piskorz, I. Komaromi, R. Gomperts, R. L. Martin, D. J. Fox, T. Keith, M. A. Al-Laham, C. Y. Peng, A. Nanayakkara, C. Gonzalez, M. Challacombe, P. M. W. Gill, B. Johnson, W. Chen, M. W. Wong, J. L. Andres, C. Gonzales, M. HeadGordon, E. S. Replogle, J. A. Pople, Gaussian 98, revision A.7, Gaussian, Inc., Pittsburgh, PA, 1998 ${ }^{28}$ U. Ohms and H. Guth, Z. Krist. 166, 213 (1984).

${ }^{29}$ E. Litonska, Z. Proba, I. Kulakowska, and K. L. Wierzchowski, Acta. Biochim. Pol. 26, 39 (1979).

${ }^{30}$ S. F. Boys and F. Bernardi, Mol. Phys. 19, 553 (1970).

${ }^{31}$ L. Túri and J. J. Dannenberg, J. Phys. Chem. 97, 2488 (1993).

32. I. Szydłowska, Y. Nosenko, B. Brutschy, P. Tarakeshwar and J. Herbich, Phys. Chem. Chem. Phys., 9, 4981 (2007).

33. I. Szydlowska, Y. Nosenko, B. Brutschy and J. Herbich, Chem. Phys. Lett. 467, 58 (2008).

${ }^{34}$ V. Barone and M. Cossi, J. Phys. Chem. A 102, 1995 (1998).

${ }^{35}$ C. Reichardt Solvent and solvent effects in organic chemistry, 3rd ed. (Weinheim, Basel 2003).

${ }^{36}$ S. Miertus, E. Scrocco, and J. Tomasi, Chem. Phys. 55, 117 (1981). 
37. W. Sudholt, A. Staib, A. L. Sobolewski and W. Domcke, Phys. Chem. Chem. Phys., 2, 4341 (2000).

${ }^{38}$ I. Pápai and G. Jancsó, J. Phys. Chem. A 104, 2132 (2000). 
Table 1. Calculated properties of the isolated methanol molecule

\begin{tabular}{|c|c|}
\hline \multicolumn{2}{|c|}{$\mathrm{MeOH}$} \\
\hline$d_{\mathrm{OH}} / \AA$ & 0.961 \\
\hline$d_{\mathrm{OC}} / \AA$ & 1.425 \\
\hline$\alpha_{\mathrm{HOC}}$ & $108.8^{\circ}$ \\
\hline$\mu / \mathrm{D}$ & 1.89 \\
\hline$v_{\mathrm{OH}} / \mathrm{cm}^{-1}$ & 3846 \\
\hline$q\left(\mathrm{H}_{\mathrm{OH}}\right) / \mathrm{e}$ & 0.253 \\
\hline$q(\mathrm{O}) / \mathrm{e}$ & -0.620 \\
\hline
\end{tabular}


Table 2. Properties of the isolated compounds (for the notation see Figure 1).

\begin{tabular}{|c|c|c|c|c|c|c|c|c|c|c|c|}
\hline & $\mathrm{BN}$ & $\mathrm{ABN}$ & $\mathrm{MABN}$ & DMABN & PY & AP & MAP & DMAP & $\mathrm{AN}$ & MAN & DMAN \\
\hline \multicolumn{12}{|l|}{$d / \AA$} \\
\hline$d_{1}$ & - & 1.015 & 1.006 & 1.463 & - & 1.008 & 1.007 & 1.456 & 1.009 & 1.008 & 1.454 \\
\hline$d_{2}$ & - & 1.015 & 1.450 & 1.463 & - & 1.008 & 1.450 & 1.456 & 1.009 & 1.451 & 1.454 \\
\hline$d_{3}$ & 1.084 & 1.438 & 1.373 & 1.438 & 1.084 & 1.383 & 1.373 & 1.377 & 1.398 & 1.390 & 1.392 \\
\hline$d_{4}$ & 1.395 & 1.397 & 1.413 & 1.401 & 1.392 & 1.403 & 1.406 & 1.413 & 1.403 & 1.405 & 1.412 \\
\hline$d_{5}$ & 1.391 & 1.389 & 1.380 & 1.389 & 1.394 & 1.388 & 1.391 & 1.388 & 1.391 & 1.395 & 1.391 \\
\hline$d_{6}$ & 1.403 & 1.403 & 1.407 & 1.403 & 1.337 & 1.339 & 1.336 & 1.338 & 1.395 & 1.392 & 1.393 \\
\hline$d_{7}$ & 1.432 & 1.431 & 1.426 & 1.431 & - & - & - & - & 1.395 & 1.397 & 1.393 \\
\hline$d_{8}$ & 1.156 & 1.156 & 1.157 & 1.156 & - & - & - & - & - & - & - \\
\hline \multicolumn{12}{|l|}{ angle ${ }^{\circ}$} \\
\hline$\alpha$ & - & 107.4 & 117.1 & 112.5 & - & 114.1 & 117.1 & 118.4 & 112.2 & 115.1 & 117.1 \\
\hline$\beta$ & - & 111.4 & 124.0 & 113.5 & - & 117.4 & 123.6 & 119.8 & 115.6 & 122.1 & 119.1 \\
\hline$\gamma$ & 119.9 & 123.0 & 119.8 & 118.5 & 120.7 & 121.5 & 122.7 & 122.2 & 120.6 & 119.6 & 121.3 \\
\hline$\delta$ & 120.2 & 118.9 & 118.2 & 119.0 & 118.6 & 116.9 & 116.6 & 115.7 & 118.6 & 118.3 & 117.3 \\
\hline$\varepsilon$ & 120.2 & 120.8 & 121.0 & 120.8 & 118.5 & 119.0 & 118.9 & 119.5 & 120.5 & 120.8 & 121.0 \\
\hline$\varphi$ & 119.7 & 119.8 & 120.6 & 119.9 & 123.6 & 124.5 & 124.9 & 124.9 & 120.8 & 120.7 & 121.2 \\
\hline$\lambda$ & 120.1 & 119.7 & 118.6 & 119.7 & 117.3 & 116.0 & 115.8 & 115.5 & 118.9 & 118.7 & 118.4 \\
\hline$\kappa$ & 120.0 & 120.2 & 120.6 & 120.1 & - & - & - & - & & & \\
\hline$\eta$ & 180.0 & 180.0 & 179.9 & 180.0 & - & - & - & - & - & - & - \\
\hline$\mu / \mathrm{D}$ & 4.74 & 5.00 & 7.65 & 5.18 & 2.37 & 4.07 & 4.64 & 4.83 & 1.59 & 1.86 & 1.99 \\
\hline \multicolumn{12}{|l|}{$q / \mathrm{e}$} \\
\hline$q\left(\mathrm{~N}_{\text {amino }}\right)$ & - & -0.496 & -0.872 & -0.633 & - & -0.701 & -0.766 & -0.835 & -0.681 & -0.756 & -0.847 \\
\hline$q(\mathrm{~N})$ & -0.372 & -0.388 & -0.489 & -0.399 & -0.398 & -0.558 & -0.587 & -0.599 & - & - & - \\
\hline \multicolumn{12}{|l|}{$v / \mathrm{cm}^{-1}$} \\
\hline$v_{\mathrm{sym}(\mathrm{NH})}$ & - & 3498 & - & - & - & 3585 & - & - & 3666 & - & - \\
\hline$v_{\text {asym }(\mathrm{NH})}$ & - & 3569 & - & - & - & 3689 & - & - & 3569 & - & - \\
\hline$v_{(\mathrm{NH})}$ & - & - & 3648 & - & - & - & 3644 & - & - & 3622 & - \\
\hline$v_{(\mathrm{CN})}$ & 2332 & 2331 & 2318 & 2331 & - & - & - & - & - & - & - \\
\hline
\end{tabular}


Table 3. Comparison of experimental and theoretical geometries of DMAP. (For the notation see Figure 1.)

\begin{tabular}{|c|c|c|c|}
\hline & $\begin{array}{c}\text { Experiment } \\
28,29\end{array}$ & $\begin{array}{c}\text { Szydlowska } \\
\text { et al. }\end{array}$ & This study \\
\hline$d / \AA$ & & & \\
\hline$d_{6}$ & $137.7(.3)$ & 134.1 & 133.8 \\
\hline$d_{6^{\prime}}$ & $133.5(.3)$ & 134.1 & 133.8 \\
\hline$d_{5}$ & $138.1(.3)$ & 139.0 & 138.8 \\
\hline$d_{5^{\prime}}$ & $137.5(.3)$ & 139.0 & 138.8 \\
\hline$d_{4^{\prime}}$ & $140.3(.2)$ & 141.4 & 141.3 \\
\hline$d_{4}$ & $140.4(.3)$ & 141.4 & 141.3 \\
\hline$d_{3}$ & $136.7(.2)$ & 137.8 & 137.7 \\
\hline$d_{1}$ & $145.2(.3)$ & 145.4 & 145.6 \\
\hline$d_{2}$ & $145.2(.3)$ & 145.4 & 145.6 \\
\hline angle ${ }^{\circ}$ & & & \\
\hline$\lambda$ & $114.5(.2)$ & 115.2 & 115.5 \\
\hline$\delta$ & $116.1(.2)$ & 115.8 & 115.7 \\
\hline$\alpha$ & $118.3(.2)$ & 119.0 & 118.4 \\
\hline$\mu / \mathrm{D}$ & 4.22 & 4.55 & 4.83 \\
\hline
\end{tabular}


Table 4. Corrected binding energies of the methanol complexes in $\mathrm{kJ} / \mathrm{mol}$

\begin{tabular}{|c|c|c|c|c|c|c|c|c|c|c|c|}
\hline$\Delta E$ & BN & ABN & MABN & DMABN & PY & AP & MAP & DMAP & AN & MAN & DMAN \\
\hline 'a' & - & $\mathbf{- 5 3 . 4 3}$ & -21.82 & - & - & -19.81 & -19.68 & - & -16.09 & -15.99 & - \\
\hline 'b' & - & -45.49 & -11.94 & -37.50 & - & -14.90 & -13.25 & $\mathbf{- 1 1 . 5 4}$ & -19.13 & -17.59 & -15.67 \\
\hline ' $\mathrm{c}^{\prime}$ & -18.19 & -52.10 & -21.10 & -48.75 & -25.85 & -28.96 & -30.03 & -30.26 & - & - & - \\
\hline
\end{tabular}


Table 5. Hydrogen bond lengths and angles in the complexes

\begin{tabular}{|c|c|c|c|c|c|c|c|c|c|c|c|}
\hline$d_{(\mathrm{A} . \mathrm{H})} / \AA$ & BN & ABN & MABN & DMABN & PY & AP & MAP & DMAP & AN & MAN & DMAN \\
\hline$d_{\mathrm{a}}$ & - & 1.993 & 1.994 & - & - & 2.002 & 2.007 & - & 2.042 & 2.046 & - \\
\hline$d_{\mathrm{b}}$ & - & 2.081 & 2.094 & $\mathbf{2 . 1 0 4}$ & - & 2.072 & 2.082 & 2.090 & 2.029 & 2.028 & 1.987 \\
\hline$d_{\mathrm{c}}$ & 2.076 & 2.049 & 2.044 & 2.042 & 1.941 & 1.914 & 1.907 & $\mathbf{1 . 9 0 5}$ & - & - & - \\
\hline$\varphi_{(\mathrm{O}-\mathrm{H}-\mathrm{N})} /{ }^{\circ}$ & $\mathrm{BN}$ & ABN & MABN & DMABN & PY & AP & MAP & DMAP & AN & MAN & DMAN \\
\hline$\varphi_{\mathrm{a}}$ & - & 174.0 & 176.2 & - & - & 176.4 & 173.7 & - & 173.8 & 173.2 & - \\
\hline$\varphi_{\mathrm{b}}$ & - & 163.8 & $\mathbf{1 6 1 . 2}$ & 162.0 & - & 165.4 & 162.4 & 163.8 & 170.2 & 168.7 & 168.5 \\
\hline$\varphi_{\mathrm{c}}$ & 176.0 & 176.0 & 175.4 & 172.1 & 174.5 & 179.1 & $\mathbf{1 7 9 . 2}$ & $\mathbf{1 7 9 . 2}$ & - & - & - \\
\hline
\end{tabular}


Table 6. Changes of selected parameters during the complex formation. The distances are given in $\AA$, the charges in elementary units and the frequencies in $\mathrm{cm}^{-1}$.

\begin{tabular}{|c|c|c|c|c|c|c|c|c|c|c|c|}
\hline 'a' & $\mathrm{BN}$ & $\mathrm{ABN}$ & MABN & DMABN & PY & AP & MAP & DMAP & AN & MAN & DMAN \\
\hline$\mu / \mathrm{D}$ & - & 9.53 & 10.00 & - & - & 6.32 & 6.66 & - & 3.82 & 4.14 & - \\
\hline$\Delta d_{1}$ & - & -0.001 & 0.006 & - & - & 0.006 & 0.006 & - & 0.005 & 0.004 & - \\
\hline$\Delta d_{3}$ & - & -0.064 & -0.008 & - & - & -0.009 & -0.008 & - & -0.008 & -0.010 & - \\
\hline$\Delta q\left(\mathrm{~N}_{\mathrm{a}}\right)$ & - & 0.398 & -0.096 & - & - & -0.087 & -0.089 & - & -0.084 & -0.093 & - \\
\hline$\Delta q(\mathrm{~N})$ & - & -0.112 & -0.036 & - & - & -0.031 & -0.031 & - & - & - & - \\
\hline$\Delta v_{\mathrm{NH}}$ & - & 95 & -106 & - & - & -18 & -96 & - & -16 & -64 & - \\
\hline$\Delta v_{\mathrm{CN}}$ & - & -15 & -5 & - & - & - & - & - & - & - & - \\
\hline$\Delta d_{\mathrm{OH}}$ & - & 0.000 & 0.000 & - & - & 0.000 & 0.000 & - & 0.000 & 0.000 & - \\
\hline$\Delta v_{\mathrm{OH}}$ & - & 1 & 1 & - & - & 2 & 1 & - & 2 & 1 & - \\
\hline 'b' & & $\mathrm{ABN}$ & MABN & DMABN & PY & $\mathrm{AP}$ & MAP & DMAP & $\mathrm{AN}$ & MAN & DMAN \\
\hline$\mu / \mathrm{D}$ & - & 4.27 & 4.92 & 5.41 & - & 1.96 & 2.42 & \begin{tabular}{|l|}
2.70 \\
\end{tabular} & 2.45 & 2.05 & 2.10 \\
\hline$\Delta d_{1}$ & - & -0.003 & 0.005 & 0.002 & - & 0.004 & 0.005 & 0.010 & 0.003 & 0.004 & 0.017 \\
\hline$\Delta d_{3}$ & - & -0.038 & 0.021 & -0.040 & - & 0.017 & 0.020 & 0.020 & 0.015 & 0.019 & 0.033 \\
\hline$\Delta q\left(\mathrm{~N}_{\mathrm{a}}\right)$ & - & -0.315 & -0.022 & -0.352 & - & -0.022 & -0.030 & -0.045 & -0.017 & -0.023 & 0.011 \\
\hline$\Delta q(\mathrm{~N})$ & - & -0.046 & 0.034 & -0.068 & - & 0.035 & 0.045 & 0.049 & - & - & - \\
\hline$\Delta v_{\mathrm{NH}}$ & - & 66 & -67 & - & - & -51 & -66 & - & -48 & -54 & - \\
\hline$\Delta v_{\mathrm{CN}}$ & - & -15 & 6 & -8 & - & - & - & - & - & - & - \\
\hline$\Delta d_{\mathrm{OH}}$ & - & 0.007 & 0.007 & 0.007 & - & 0.008 & 0.008 & 0.008 & 0.010 & 0.011 & 0.013 \\
\hline$\Delta v_{\mathrm{OH}}$ & - & -140 & -150 & -145 & - & -160 & -160 & -157 & -209 & -216 & -264 \\
\hline 'c' & & $\mathrm{ABN}$ & MABN & DMABN & PY & $\mathrm{AP}$ & MAP & DMAP & AN & MAN & DMAN \\
\hline$\mu / \mathrm{D}$ & 7.07 & 9.25 & 10.22 & \begin{tabular}{|l|}
10.55 \\
\end{tabular} & 4.80 & 6.88 & 7.35 & 7.68 & - & - & - \\
\hline$\Delta d_{1}$ & - & -0.008 & 0.000 & -0.007 & - & -0.001 & 0.000 & 0.001 & - & - & - \\
\hline$\Delta d_{3}$ & 0.000 & -0.058 & -0.004 & -0.064 & 0.000 & -0.006 & -0.005 & -0.006 & - & - & - \\
\hline$\Delta q\left(\mathrm{~N}_{\mathrm{a}}\right)$ & - & -0.321 & -0.023 & -0.331 & - & -0.032 & -0.027 & -0.022 & - & - & - \\
\hline$\Delta q(\mathrm{~N})$ & -0.094 & -0.192 & -0.125 & -0.231 & -0.057 & -0.079 & -0.085 & -0.089 & - & - & - \\
\hline$\Delta v_{\mathrm{NH}}$ & - & 98 & 80 & - & - & 11 & \begin{tabular}{|l|}
7 \\
\end{tabular} & - & - & - & - \\
\hline$\Delta v_{\mathrm{CN}}$ & 9 & -3 & 7 & 3 & - & - & - & - & - & - & - \\
\hline$\Delta d_{\mathrm{OH}}$ & 0.006 & 0.007 & 0.007 & 0.007 & 0.014 & 0.017 & 0.017 & 0.018 & - & - & - \\
\hline$\Delta v_{\mathrm{OH}}$ & -94 & -116 & -194 & -121 & -284 & -328 & -341 & -345 & - & - & - \\
\hline
\end{tabular}


Table 7. Selected data of the hexafluoro-propan-2-ol complexes

\begin{tabular}{|c|c|c|c|c|}
\hline & 'c' PY & 'b' DMAP & 'c' DMAP & 'b' DMAN \\
\hline$\Delta E / \mathrm{kJ} / \mathrm{mol}$ & -48.14 & -15.85 & -57.89 & $-24.34^{*}$ \\
\hline$\mu / \mathrm{D}$ & 7.65 & 5.79 & 11.17 & 5.34 \\
\hline$d_{\mathrm{N} . \mathrm{H}} / \AA$ & 1.750 & 1.902 & 1.703 & 1.805 \\
\hline$\Delta q\left(\mathrm{~N}_{\text {amino }}\right)$ & - & 0.653 & 0.853 & 0.642 \\
\hline$\Delta q\left(\mathrm{~N}_{\text {pyridine }}\right)$ & -0.087 & 0.517 & 0.372 & - \\
\hline$\Delta d(\mathrm{O}-\mathrm{H}) / \AA$ & 0.030 & 0.019 & 0.038 & 0.027 \\
\hline
\end{tabular}

without BSSE correction 
Table 8. Changes of selected parameters of DMAP in different solvents. The distances are in pm-s, the partial charges in elementary units.

\begin{tabular}{|c|c|c|c|c|c|c|c|}
\hline & \multirow[b]{2}{*}{ gas phase } & \multicolumn{6}{|c|}{ changes with respect to gas phase } \\
\hline & & $\mathrm{CH}$ & $\mathrm{CCl}_{4}$ & DEE & $\mathrm{ClBz}$ & THF & $\mathrm{ACN}$ \\
\hline $\mathrm{N}_{\text {amino }}-\mathrm{C}_{\text {methyl }} d_{1,2}$ & 1.455 & 0.002 & 0.002 & 0.003 & 0.003 & 0.003 & 0.004 \\
\hline \begin{tabular}{l|l}
$\mathrm{C}_{\text {ring }}-\mathrm{N}_{\text {amino }}$ & $d_{3}$ \\
\end{tabular} & 1.377 & -0.004 & -0.005 & -0.007 & -0.008 & -0.009 & -0.010 \\
\hline $\mathrm{C}_{\text {ring }}-\mathrm{C}_{\text {ring }}$ & 1.413 & 0.002 & 0.002 & 0.003 & 0.004 & 0.004 & 0.005 \\
\hline $\mathrm{C}_{\text {ring }}-\mathrm{N}_{\text {ring }}$ & 1.338 & 0.003 & 0.003 & 0.005 & 0.005 & 0.006 & 0.005 \\
\hline$q\left(\mathrm{~N}_{\mathrm{amino}}\right)$ & -0.834 & 0.858 & 0.857 & 0.850 & 0.848 & 0.850 & 0.844 \\
\hline$q\left(\mathrm{~N}_{\text {pyridine }}\right)$ & -0.599 & 0.433 & 0.426 & 0.388 & 0.378 & 0.369 & 0.347 \\
\hline$\mu / \mathrm{D}$ & 4.83 & 0.80 & 0.89 & 1.36 & 1.48 & 1.59 & 1.89 \\
\hline
\end{tabular}




\section{Figure captions}

Figure1. Schematic view and abbreviations of the examined compounds. Bonds are numbered as shown; the Greek letters indicate bond angles. 
$A B N: R_{1}=H, R_{2}=H$
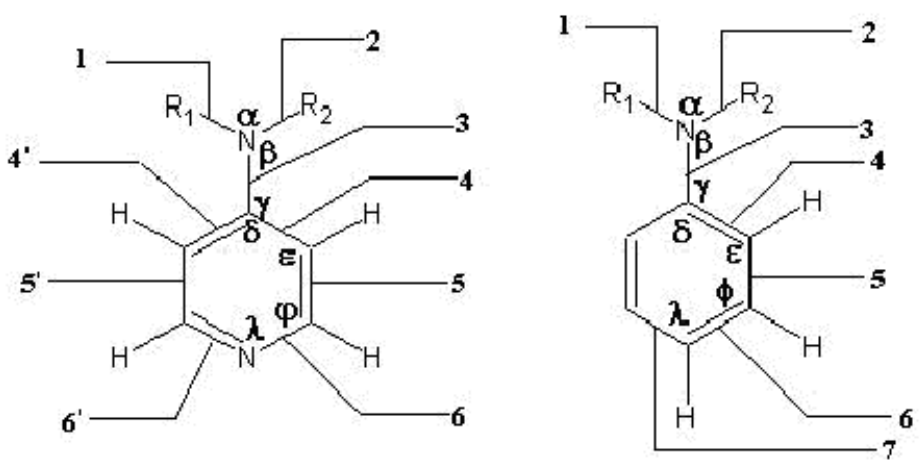

AP: $\mathrm{R}_{1}=\mathrm{H}, \mathrm{R}_{2}=\mathrm{H}$

MAP: $\mathrm{R}_{1}=\mathrm{H}, \mathrm{R}_{2}=\mathrm{CH}_{3}$ DMAP : $\mathrm{R}_{1}=\mathrm{CH}_{3}, \mathrm{R}_{2}=\mathrm{CH}_{3}$ Py: $-N R_{1} R_{2}$ replaced by $H$
AN: $R_{1}=H, R_{2}=H$ MAN: $\mathrm{R}_{1}=\mathrm{H}, \mathrm{R}_{2}=\mathrm{CH}_{3}$ DMAN: $\mathrm{R}_{1}=\mathrm{CH}_{3}, \mathrm{R}_{2}=\mathrm{CH}_{3}$

MABN: $\mathrm{R}_{1}=\mathrm{H}, \mathrm{R}_{2}=\mathrm{CH}_{3}$

DMABN: $\mathrm{R}_{1}=\mathrm{CH}_{3}, \mathrm{R}_{2}=\mathrm{CH}_{3}$

BN: - $-\mathrm{NR}_{1} \mathrm{R}_{2}$ replaced by $\mathrm{H}$

Figure1. Schematic view and abbreviations of the examined compounds. Bonds are numbered as shown; the Greek letters indicate bond angles. 